\title{
Portafolios de experiencias docentes, el profesor como investigador de su práctica
}

The portfolios of teaching experience, the teacher as researcher of his exercise

Carteiras de experiências de ensino, professor e pesquisador prática

\author{
Martín Aram Omar Guerrero Calderón \\ Universidad de Guanajuato, México \\ aramguerreroc@hotmail.com
}

\section{Resumen}

El presente trabajo da cuenta del análisis realizado a la modalidad de titulación "Portafolios de experiencias docentes" en tanto herramienta que da cuenta del proceso mediante el cual el profesor tiene la posibilidad de convertirse en investigador de su propia práctica a la vez que cumple con el objetivo de la Maestría en Desarrollo Docente, reflexionar críticamente e integrar elementos teóricos a su labor cotidiana; permitiendo innovar en su quehacer, siguiendo paso a paso la metodología de la investigación-acción del profesorado (pedagógica).

Para concretar el estudio realizado se utilizó la entrevista a profundidad y la revisión de los portafolios de experiencia docente, de los alumnos titulados bajo esta modalidad en la primera generación (2012 - 2016) y los próximos a titularse de la segunda generación (2014-2016).

Palabras clave: Portafolios de experiencias docentes, investigación-acción, análisis de la práctica, innovación educativa. 


\section{Abstract}

This paper is about the analysis the mode of degree "Portfolio teaching experiences" as tool that realizes the process by which the teacher has the possibility of becoming a researcher of their own practice while meeting with the objective of the Master in Teaching Development, reflect critically and integrate theoretical elements into their daily work; enabling innovation in their work, following step by step the methodology of action research teacher (teaching).

And close to graduating from the second generation (2014 - 2016 - depth interviews and reviewing portfolios of teaching experience, students qualified under this system in the first generation (2016 2012) was used to finalize the study conducted ).

Key words: Portfolio teaching experiences, action research, practice analysis, educational innovation.

\section{Resumo}

Este artigo é sobre a análise do modo de grau "experiências de ensino Portfolio", como ferramenta que realiza o processo pelo qual o professor tem a possibilidade de se tornar um pesquisador de sua prática durante a reunião com o objetivo do Mestrado em Desenvolvimento de Ensino, refletir criticamente e integrar elementos teóricos em seu trabalho diário; permitindo a inovação em seu trabalho, seguindo passo a passo a metodologia do professor de pesquisa-ação (ensino).

e perto de se formar a partir da segunda geração (2014 - 2016 - entrevistas em profundidade e revisão de carteiras de experiência de ensino, os alunos qualificados sob este sistema na primeira geração (2016 2012) foi utilizado para finalizar o estudo realizado ).

Palavras-chave: experiências de ensino Portfolio, pesquisa-ação, análise prática, a inovação educacional. 


\section{Introducción}

Hablar de Portafolio de experiencias docentes como modalidad de titulación para la Maestría en Desarrollo Docente de la Universidad de Guanajuato, es hablar de un proceso de formación académica que dura al menos cuatro periodos semestrales, de este modo son varios los factores a analizar para aceptar que el conjunto de actividades desarrolladas por los estudiantes en cada una de las 4 asignaturas del eje de Innovación de la práctica en las comunidades educativas, conformen en su conjunto el documento con el que se puede obtener el grado.

No podríamos olvidar, atendiendo a la visión del Consejo Nacional de Ciencia y Tecnología (CONACYT) para los posgrados empadronados en el Plan Nacional de Posgrados de Calidad (PNPC), que se trata de una maestría profesionalizante, por lo que su finalidad es mejorar la práctica educativa de quienes la cursan, por ende, se debe partir del supuesto de que el posgrado está dirigido a profesores en servicio, mismos que elaborarán en los dos años de formación el documento que atañe a esta investigación. Son entonces dos factores que es importante no perder de vista, el portafolio de experiencias docentes es una forma de titulación de un posgrado profesionalizante, donde se busca mejorar el ejercicio pedagógico del maestrante; proceso que recorre tres etapas: caracterización, problematización e innovación.

Como elementos que gestan el interés por realizar una investigación alrededor de este documento y modalidad de titulación, se encuentran la validez académica de la que gozan tanto el portafolio como el proceso de estructuración, lo que incluye las implicaciones existentes en torno al proceso y que deben concretarse en la innovación educativa ejecutada en un plan de acción; así como la fundamentación teórica que los profesores-investigadores realizan en torno a las problemáticas que han encontrado en su propio quehacer. Es un proceso en espiral fundamentado en la investigación-acción, de ahí que conceptos como 
intervención e innovación de las prácticas educativas conformarán reflexiones en torno a los cuales se teorizará.

El proceso de elaboración del portafolio de experiencias docentes da cuenta del camino andado entre identificar y construir una problemática surgida del ejercicio docente de cada uno de los estudiantes de la maestría, hasta proponer una solución que sea llevada al aula (en su rol de profesor dentro en un grupo con características particulares), de tal modo que la práctica educativa es el objeto material de la investigación. Bajo el cual se llevará a la observación y análisis, la construcción de un problema de investigación, para llegar a la planeación-innovación y la intervención. Desde esta perspectiva se planteó una pregunta general ¿Cómo es llevado a cabo el proceso de elaboración del portafolio de experiencias docentes por los maestrantes para convertirse en investigadores de su propia práctica?

Con varios atisbos de preguntas muy particulares que ayudaron a dar respuesta de manera muy concreta a la anterior ¿Cómo es que este largo proceso se lleva a cabo?, ¿cómo lo elaboran los estudiantes?, ¿de qué forma sustentan desde la problematización hasta la intervención?, profesional y personalmente ¿qué cambios sufren los maestrantes?

Se trata de una mirada hacia la elaboración del portafolio desde quienes lo hacen, a fin de identificar los cambios ocurridos en la práctica durante su formación como maestros en Desarrollo Docente, mientras se pone en crisis la validez de dicha modalidad, a fin de sustentarla desde una perspectiva académica. Al tiempo que se describe las etapas que conforman dicho proceso y que lo hace una opción de titulación para el posgrado.

\section{Metodología de investigación}

Una vez definida la finalidad del trabajo donde el punto central es el proceso de elaboración del portafolio seguido por los estudiantes en su formación como teóricos-prácticos ${ }^{1}$ de la educación (investigadores de su ejercicio docente), es momento de tomar en cuenta a quienes fueron sujetos de análisis y el camino recorrido para lograrlo. Para ello se dio

\footnotetext{
${ }^{1}$ Ante el debate entre los llamados técnicos de la educación, es decir, los profesores quienes siguen planes y programas, además ponen en práctica las corrientes pedagógicas elaboradas por los llamados teóricos de la educación, se encuentra la visión de Stenhause (1985) quien desde la perspectiva curricular asegura no bastaría con estudiar la labor de los docentes, sino que son ellos mismos quienes necesitan estudiarla. Recordemos sus esfuerzos por incluirlos en la investigación educativa, son ellos los responsables de generar conocimientos específicos en contextos particulares.
} 
importancia a aquellos estudiantes de la primera generación titulados y los de segunda generación en vísperas de titularse por dicha modalidad, en suma, once, además se retomó la voz de las profesoras encargadas del eje bajo el cual los estudiantes realizan el portafolios. A continuación se caracteriza la muestra:

Generación 2012 - 2014

\begin{tabular}{|c|c|c|c|}
\hline Nombre & $\begin{array}{l}\text { Nivel educativo } \\
\text { en que labora. }\end{array}$ & $\begin{array}{l}\text { Formación previa al } \\
\text { posgrado. }\end{array}$ & Título \\
\hline $\begin{array}{l}\text { Rosa Sánchez } \\
\text { Titulada }\end{array}$ & $\begin{array}{l}\text { Nivel medio } \\
\text { superior }\end{array}$ & Contador Público & $\begin{array}{l}\text { El juego como estrategia didáctica para el } \\
\text { aprendizaje significativo de las Matemáticas } \\
\text { Financieras. (2014) }\end{array}$ \\
\hline $\begin{array}{l}\text { Leonardo } \\
\text { Castro } \\
\text { Titulado }\end{array}$ & $\begin{array}{l}\text { Nivel medio } \\
\text { superior }\end{array}$ & $\begin{array}{l}\text { Ingeniero en Sistemas } \\
\text { Computacionales }\end{array}$ & $\begin{array}{l}\text { Estimulación del aprendizaje } \\
\text { Pragmático/Colaborativo } \\
\text { a través del uso e incorporación de las TIC. } \\
\text { (2014) }\end{array}$ \\
\hline $\begin{array}{l}\text { Oscar Guerra } \\
\text { Titulado }\end{array}$ & $\begin{array}{l}\text { Nivel medio } \\
\text { superior. }\end{array}$ & $\begin{array}{l}\text { Lic. En educación } \\
\text { Secundaria } \\
\text { Lic. En Filosofía }\end{array}$ & $\begin{array}{l}\text { El uso del conflicto cognitivo en la enseñanza } \\
\text { de la Ética. (2014) }\end{array}$ \\
\hline $\begin{array}{l}\text { Luz Camarillo } \\
\text { Titulada }\end{array}$ & Nivel superior & Ingeniero Ambiental & Portafolio de experiencias. (2014) \\
\hline $\begin{array}{l}\text { Daniela Uresti } \\
\text { Titulada }\end{array}$ & Preescolar & $\begin{array}{l}\text { Lic. En Educación } \\
\text { Preescolar }\end{array}$ & $\begin{array}{l}\text { El juego como estrategia para favorecer el } \\
\text { lenguaje escrito en niños de segundo de } \\
\text { preescolar. (2015) }\end{array}$ \\
\hline $\begin{array}{l}\text { Martha } \\
\text { Gódinez } \\
\text { Titulada }\end{array}$ & Secundaria & $\begin{array}{l}\text { Lic. En Educación } \\
\text { Lic. En Derecho }\end{array}$ & $\begin{array}{l}\text { Propuesta de evaluación formativa en la } \\
\text { asignatura de Historia de educación } \\
\text { secundaria. (2016) }\end{array}$ \\
\hline
\end{tabular}


Generación 2014 - 2016 (En proceso de titulación)

\begin{tabular}{|l|l|l|l|}
\hline \multicolumn{1}{|c|}{ Nombre } & $\begin{array}{c}\text { Nivel educativo } \\
\text { en que labora. }\end{array}$ & $\begin{array}{l}\text { Formación previa al } \\
\text { posgrado. }\end{array}$ & \multicolumn{1}{|c|}{ Título } \\
\hline $\begin{array}{l}\text { Anahí } \\
\text { Contreras }\end{array}$ & Licenciatura & $\begin{array}{l}\text { Licenciada en la } \\
\text { Enseñanza del Inglés }\end{array}$ & $\begin{array}{l}\text { Los elementos estratégicos didácticos y } \\
\text { metodológicos a los que recurre el docente de } \\
\text { inglés para potencializar el desarrollo de la } \\
\text { habilidad pragmática en la adquisición del } \\
\text { idioma inglés como lengua extranjera. }\end{array}$ \\
\hline $\begin{array}{l}\text { Montserrat } \\
\text { López }\end{array}$ & Secundaria & $\begin{array}{l}\text { Licenciada en } \\
\text { Economía }\end{array}$ & $\begin{array}{l}\text { Análisis reflexivo de la práctica docente: Una } \\
\text { mirada intima a los procesos de aprendizaje } \\
\text { de la clase de Español en Educación } \\
\text { Secundaria. }\end{array}$ \\
\hline Esther Lerdo & $\begin{array}{l}\text { Nivel medio } \\
\text { superior }\end{array}$ & $\begin{array}{l}\text { Licenciada en } \\
\text { Comunicación }\end{array}$ & $\begin{array}{l}\text { La Creatividad como estrategia del docente en } \\
\text { el aula para el fortalecimiento de las } \\
\text { relaciones actitudinales y valorales en los } \\
\text { estudiantes del nivel medio superior. }\end{array}$ \\
\hline $\begin{array}{l}\text { Lorena } \\
\text { Hurtado }\end{array}$ & Secundaria & $\begin{array}{l}\text { Licenciada en } \\
\text { Educación } \\
\text { Secundaria con } \\
\text { especialidad } \\
\text { Telesecundaria }\end{array}$ & $\begin{array}{l}\text { Desempeño académico en el área de } \\
\text { matemáticas y su relación con la autoestima. }\end{array}$ \\
\hline Lázaro Muñoz & Licenciatura & $\begin{array}{l}\text { Ingeniero } \\
\text { Electromecánico }\end{array}$ & $\begin{array}{l}\text { Innovación en la unidad de aprendizaje de } \\
\text { diseño automotriz. }\end{array}$ \\
\hline
\end{tabular}

A fin de justificar la validez académica del Portafolio de experiencia docentes como modalidad de titulación e identificar el camino mediante el cual los cursantes de la Maestría en Desarrollo Docente se convierten en profesores-investigadores (según la propuesta de Stenhause) se retomarán dos elementos claves en la metodología de investigación cualitativa, por un lado la entrevista con los actores, es decir, la población de estudiantes que se han titulado por esta modalidad o bien que le hubiesen tomado como opción de titulación, por otro lado el análisis de los portafolios de experiencia docente, que dan cuenta del mismo proceso, elaborados hasta julio de 2016.

Se hace un acercamiento desde el paradigma cualitativo de la ciencia, ya que en la visión de Luis Porta y Miriam Silva (2003) "La realidad social no tiene un carácter objetivo, sino que es inseparable de los propios sujetos intervinientes y de sus expectativas, intenciones, sistemas de valores, etc. De cada individuo y de cómo éste percibe la realidad y su propia acción", recordemos que el documento que es objeto de análisis en el presente trabajo responde al proceso de enseñanza que cada uno de los maestrantes en su papel de profesor, llevó al aula y sistematizó por escrito, lo que sin duda se convierte en un reflejo de un conjunto de procesos internos de los cuales sólo ellos pueden dar cuenta, ya que se ven 
inmersos motivos, intenciones y acciones que responden al contexto en el que se desarrollan. Problemáticas que se originan de la interacción, con los otros (los alumnos que atienden) y que responden a la dinámica social de los actores educativos, es decir, imágenes como el profesor, los estudiantes, los padres de familia e incluso la comunidad donde éstos se desarrollan.

La pretensión de recoger datos descriptivos se justifica en algunas de las características de la metodología cualitativa de la investigación, según Taylor y Bogdan (1989) se desarrollaron conceptos partiendo de pautas de los datos, sin establecer hipótesis o tener una teoría preconcebida, en este sentido se trató de una construcción desde la problemática hasta los resultados. Fueron aceptadas como valiosas las perspectivas de los entrevistados, aceptando que no se buscaba una verdad y sí una comprensión de sus posturas. Bajo una perspectiva humanista se reconoció el aspecto interior de los involucrados, sus representaciones, sus concepciones y sus propuestas. Finalmente se escuchó a los maestrantes y se analizaron los documentos que produjeron lo que para Queceño y Castaño (2002) correspondería a dar énfasis en la validez de la investigación. Habría que recalcar que se buscan los significados para los sujetos inmersos lo que implica la posibilidad de realizar entrevistas, retomar experiencias personales, es decir, la realidad es estudiada en su contexto natural.

La entrevista es una de las herramientas más utilizadas en los métodos cualitativos de la investigación, de manera indispensable se utiliza en la Historia Oral, el Método Clínico o las Representaciones sociales, y como complemento para la etnografía o la investigación acción. Cuando Taylor y Bogdan² (1989) definen la entrevista recurren a Benney y Hughes, asegurando que para los sociólogos en tanto científicos sociales "es la herramienta de excavar" (pág. 100), para definirlo como método cualitativo de investigación le nombran entrevistas en profundidad y le definen así:

\footnotetext{
${ }^{2}$ Recordemos que Taylor y Bogdan ven en la entrevista un método de investigación cualitativa, a la que caracterizan como no directiva, no estructurada, no estandarizada y abierta, a las entrevistas cualitativas les dan el nombre de entrevista en profundidad, diferenciándola de la entrevista aplicada a un grupo grande de sujetos a la que denominan entrevista estructurada, donde a las personas se les formulan las preguntas en términos idénticos a fin de comparar los resultados.
} 
"Por entrevistas cualitativas en profundidad entendemos reiterados encuentros cara a cara entre el investigador y los informantes, encuentros éstos dirigidos hacia la comprensión de las perspectivas que tienen los informantes respecto de sus vidas experiencias o situaciones, tal como lo expresan en sus propias palabras... el propio investigador es el instrumento de la investigación y no lo es un protocolo o formulario de entrevista." (Taylor y Bogdan, 1989, pág. 101)

De tal modo que es la entrevista el medio para realizar la presente investigación, conociendo por las fuentes las acciones que se llevan a cabo durante el proceso de elaboración del portafolio, las necesidades a las que responden y las percepciones en torno a ello, si bien, la propuesta considera no llevar un cuestionario establecido, una de las características mencionada por estos autores sobre la entrevista deja en claro que los intereses de la investigación deben ser relativamente claros y estar congruentemente definidos, por ello es que se establecieron 3 criterios que serían las guías de las charlas con los informantes: concepciones sobre el Portafolio de experiencias docentes (en tanto modalidad de titulación para posgrado), proceso de elaboración del Portafolio y resultados obtenidos.

Se ha planteado que es ésta relación entre profesor-investigador el punto de observación a través de la entrevista y el portafolio, no se podría pensar en la revisión alrededor de un texto que no ha sido definido, ni descrito, es importante recuperar la visión que los estudiantes tienen sobre la evidencia que ha de darles el grado de maestros y la rigurosidad con que es elaborado por ellos, a fin de validarlo desde la metodología cualitativa específicamente desde la investigación-acción.

Las entrevistas realizadas a cada uno de los estudiantes de la maestría y a las coordinadoras del eje innovación de la práctica en comunidades de aprendizaje, fueron transcritas y analizadas con base en los criterios antes mencionados, estableciendo algunas variables por criterio para formalizar el análisis del discurso, mismo que se presentará más delante; en este mismo tenor se analizaron los 11 portafolios para reforzar lo conducente a la segunda y la tercer categoría, con la finalidad de reconocer cada una de las fases que conforman los documentos de titulación. Si bien no son diarios o relatos sobre su vida, sí se trata de textos que implican la reflexión sobre un tema específico en su vida profesional (Taylor y 
Bogdan, 1989), como lo son los procesos de enseñanza - aprendizaje que llevan en conjunto con sus estudiantes dentro del aula.

Fueron entonces tomados en cuenta dos tipos de referentes para entenderles como documentos personales, en primer lugar son una fuente de datos generados desde su intimidad, además presentan una reflexión sobre sus propias experiencias inmediatas (Taylor y Bogdan, 1989, pág. 141), recordemos que finalmente en el cúmulo de trabajos están presentes las reflexiones que en su papel de docentes hacen sobre los acontecimientos generados en el aula; el registro ampliado, por ejemplo, lleva una columna en la que el profesor va realizando los juicios y acotaciones en torno a lo sucedido el aula. El registro simple, es en sentido estricto, una evidencia de la práctica sin más filtro, que la búsqueda de ser un espejo fiel de lo ocurrido en la clase.

Sin embargo la estructura formal de los registros, ensayos y fundamentaciones teóricas que le conforman no pueden ser tratados de otra forma más que desde el análisis propio del discurso, en un acercamiento por hacer hermenéutica ${ }^{3}$, para Gadamer (Mardones, 1991) el lenguaje es el medio en el que tienen lugar la comprensión, la forma de realización de la comprensión es la interpretación. El lenguaje es luego el medio universal para ponerse de acuerdo con alguien sobre algo, el espacio para el consenso. El lenguaje es entonces desde esta perspectiva el mediador de la experiencia hermenéutica ${ }^{4}$. Si los seres humanos tenemos finalidades implícitas en nuestros actos, y según Mardones éstos desde la hermenéutica pueden leerse, deben existir también en el discurso intenciones vertidas a las cuales acercarse.

Los portafolios de experiencias docentes se revisaron con una finalidad de comprensión o bien de interpretación, para contrastarse con lo expuesto por sus autores en las entrevistas. Existe pues la posibilidad de abrir un doble canal de comunicación que va del texto escrito a la oralidad, a fin de encontar los caminos seguidos por los estudiantes en búsqueda de la obtención del grado, mismo que se logra en la medida que sean capaces de desarrollar una serie de competencias durante su formación. Esta es pues la oportunidad de sentido literal

\footnotetext{
${ }^{3}$ Gadamer, no entiende la hermenéutica como un método, sino, la posibilidad de comprensión del discurso.

${ }^{4}$ En la visión de Habermas, para llegar incluso a la argumentación es necesario primero acercarse a la comprensión, sin entrar a las discusiones entre ambos autores, es válido recordar que la hermenéutica debe encontrarse al mismo nivel de la teoría y la práctica.
} 
para establecer un diálogo, que permita identificar si el estudiante de maestría dentro del aula se hace de las herramientas para convertirse en investigador de su propia práctica, tomando referentes teóricos que le permitan, construir un problema, proponer una solución (elemento que sin duda debe incluir la innovación) llevarlo a la práctica y evaluarla.

\section{Contextualización del portafolio como modalidad de titulación.}

En mayo de 2011 se aceptó por el consejo General Universitario el programa de estudios de la Maestría en Desarrollo Docente para fortalecer los programas del Departamento de Educación (La Licenciatura en Educación y la Maestría en Investigación Educativa) algunos de los egresados del posgrado ya existente manifestaron la necesidad de cursar un programa que les permitiera hacerse de las herramientas para la mejora de su práctica, por otro lado es un tema recurrente en las universidades el fortalecimiento de su propia planta docente, al aceptar que se carece de formación en el ámbito pedagógico. Fue así como fue elaborado el rediseño de la Maestría en Desarrollo Docente, quien en su competencia general marca como objetivo:

"Formar profesionales con grado de Maestría en Desarrollo Docente quienes con un sólido sustento científico-tecnológico, humanista y con amplio compromiso social en la promoción de valores humanos, logren a través de la reflexión crítica y la integración de la teoría a su labor cotidiana, aplicar avances y los nuevos enfoques de las ciencias de la educación, a fin de innovar la práctica educativa en función de los retos de la sociedad contemporánea.” (UG, 2014)

Hay desde ahora dos elementos que subyacen al presente trabajo la incorporación de la teoría y la reflexión crítica como base para formar al estudiante del posgrado en investigador de su propia práctica y como resultado de este proceso la innovación educativa, además de permitir justificar, como se presentará más adelante, el uso de la investigación-acción como metodología para lograr dicho objetivo. Es a raíz de esta problemática que la maestría presenta dos modalidades de titulación: elaboración de tesis y examen general de conocimientos. 
Ésta última modalidad con tres opciones: ensayo, presentación escrita de un tema y portafolios de experiencias docente. A fin de realizar el análisis de esta modalidad ha sido necesario generar un marco conceptual que permita explicar y obtener conclusiones se presentará elementos teóricos con la información presentada en las entrevistas a fin de relacionar las ideas y generar concepciones de lo que se presenta en la realidad durante la formación de los profesores.

\section{Concepción el Portafolio de Experiencias Docentes}

No existe desde la propia institución una definición, que sí una estructura definida, de Portafolios de experiencias docentes, sin embargo, al tratarse de una modalidad de titulación, debe dar cuenta de lo expuesto en el objetivo: reflexión crítica, integración de la teoría y la innovación en el ejercicio. El documento se elabora con las actividades que cada semestre se realizan en las asignaturas del eje de innovación de la práctica en las comunidades de aprendizaje: Recuperación y análisis de la práctica docente, Innovación de la práctica docente (en dos cursos) y Seminario de titulación. El conjunto de actividades está predeterminado desde la coordinación de la maestría, y da cuenta de tres etapas: caracterización, problematización e innovación. Mientras que para lograrlo se utiliza el modelo metodológico de la investigación acción.

En sentido general un portafolios es un instrumento de recolección de evidencias, mismas que pueden utilizarse con fines de evaluación, dan cuenta de lo que un estudiante pudo aprender durante un determinado periodo. De acuerdo con Frida Díaz Barriga (2012) lo que ella denomina portafolio de aprendizaje es una selección o colección de trabajos académicos que los alumnos han realizado en el transcurso de un ciclo o curso escolar aunque también sustentado en alguna dimensión temporal o ajustándose a un proyecto de trabajo dado, para el caso de maestría, hay un objetivo que se debe alcanzar, relacionado con la mejora de la actividad docente, desde un marco teórico y con intenciones claras para lograr desarrollar los aprendizajes esperados acorde a la asignatura y nivel educativo en que cada uno de los maestrantes se desempeña. 
Al presentarse como modalidad de titulación su función es prioritariamente evaluativa, es preciso demostrar que los cursantes logran el objetivo del programa, por ende, lo que tiene ciertas ventajas si se recuerda a Barberá (2005) al reconocer el carácter procesual no sólo de la enseñanza y del aprendizaje sino también de la evaluación en cuanto proceso de progresiva información compartida entre estudiante y profesor en el alcance paulatino de la mejora continua. Es realmente un ejercicio de metareflexión, pues no solo se queda en el plano de realizar cada una de las actividades que implican la descripción de la propia práctica, la intención real es llegar al análisis de la misma.

Para exponer con claridad el concepto generado a partir de la puesta en marcha del posgrado se hace alusión a la visión de las coordinadoras del eje, para quienes el portafolio de experiencias docentes:

"Es el recuento de un proceso, un recorrido muy personal, un encuentro consigo mismo y poder evidenciar parte de ese proceso, muy humano, y que tiene muchas caras es muy difícil dar cuenta de todo pero si se puede por lo menos dentro del proceso, digamos académico profesional también dar cuenta de un proceso personal de transformación y de cambio, que por supuesto esperamos que sea para mejorar." (Galván, comunicación personal, 13 de abril de 2016)

"Para mí el portafolio de experiencias es como un proyecto muy particular, de cada persona, como de su práctica, porque todo va enfocado a la práctica del profesor, entonces más bien yo lo veo como relacionado con el proyecto pero que va ligado a tu práctica docente, o sea todo es desde lo tuyo como desde tu que hacer como profesor" (Velázquez, comunicación personal, 13 de abril de 2016)

Dos características habría que resaltar en las intervenciones, se trata de un proceso que une el ámbito profesional con el personal, una transformación en búsqueda de la mejora; en ese mismo sentido al ser un proceso e incorporar un proyecto de mejora es completamente personal porque implica algo tan individual como el desempeño del sujeto frente a los otros en el aula, es decir; si bien desde el mapa curricular del posgrado hay una dirección común, la realización del trabajo se realiza en lo individual, porque así es la práctica docente, 
analizarla ${ }^{5}$ es proponer retos nacidos del contexto en el que el profesor trabaja, atender a la alteridad con quien se relaciona desde sus propias necesidades tomando en cuenta las limitaciones de ambas partes.

Es importante no perder de vista dos elementos, el portafolios es elaborado por el estudiante de maestría en su faceta de profesor, juega un doble rol, el portafolio es un instrumento de evaluación en tanto que cursa un programa de posgrado, es evaluado por un docente quien debe dar seguimiento a las actividades para que el estudiante-profesor cumpla con las habilidades necesarias para reflexionar sobre la práctica, mientras incorpora elementos teóricos a la innovación que lleva en el aula; pero es también y de ahí su nombre, Portafolios de experiencia docente, un conjunto de evidencias de su práctica como responsable de los procesos de enseñanza y aprendizaje en el salón de clase.

El portafolio docente en el cercamiento hecho por Bozu (2012, pág. 14) existe "un elevado consenso en considerar el portafolio como una colección de materiales seleccionados con la intención de explicar el rendimiento o el aprendizaje realizado a lo largo de un proceso de formación, reflexionar sobre ello y evaluarlo." Además la misma autora explica que hacia 1980 se utilizó principalmente con fines acreditativos y de certificación de las competencias profesionales adquiridos por el profesorado durante un proceso formativo o a lo largo de su trayectoria profesional hasta convertirse en lo que ella llama un nuevo instrumento de profesionalismo docente y agrega que actualmente se utiliza "con fines formativos para la mejora y el desarrollo profesional de la función docente.”(Pág. 10). Estas visiones coinciden con lo expuesto por los estudiantes:

"Es analizar lo que tú haces en la práctica, a través de unas consideraciones teóricas o sucesos o metodologías teóricas para relacionar lo quieres hacer en el aula, también puedes tu mejorar, cambiar, de esa práctica docente llevas al aula a través de esos teóricos; das una clase y tú crees que la das bien sin tener el conciliación que hay otros que han investigado cuestiones en docencia y que con base en esas

\footnotetext{
${ }^{5}$ Inés Lozano y Eduardo Mercado (2014) observan que para analizar "la práctica" se requieren herramientas teóricas y metodológicas, que permitan una vez descrita distanciarse de ellas, es decir, hacer extraño algo que pareciera tan familiar.
} 
investigaciones para poder mejorar" (López, comunicación personal, 13 de abril de 2016)

"Es recuperar las experiencias vividas de enseñanza-aprendizaje, someterlo a un análisis y reflexión del docente para poder regresar, mejorar, modificar, cambiar esa práctica y que a la vez este, digamos, en esa reflexión constante de ello mediante a estas actividades que realizas a diario. Yo lo veo como un cúmulo de evidencias de las experiencias que se tienen tanto en la parte teórica que vemos en clase y su aplicación en nuestro contexto como docentes veo que es un proceso bien estructurado que no solamente como la tesis abarca la parte de investigación sino también la aplicación y no solamente abarca un periodo especifico en la maestría sino es todo el proceso" (Contreras, comunicación personal, 13 de abril de 2016)

Puede concluirse que el Portafolio es un documento realizado por el estudiante de maestría sobre su quehacer como docente en el aula, es el conjunto de evidencias del proceso, que va de la observación, y la definición de un problema gestado en el contexto del aula; para resolverlo el estudiante-profesor debe recurrir a la teoría para explicarlo, definirlo y proponer una solución que implique la innovación de su actuar frente a los estudiantes para aplicarlo, recoger los resultados y evaluarlos. Según lo propone Bozú (2012, pág. 19) permite el desarrollo de la docencia pues "proporciona la oportunidad de reflexionar de forma crítica y valorativa sobre su actuación docente, con el fin de fomentar la mejora de la calidad de su desempeño profesional y el aprendizaje de nuevas e innovadoras ideas en el proceso de enseñanza-aprendizaje."

\section{Proceso de elaboración del portafolio de experiencias docentes}

Uno de los aspectos que desde la perspectiva metodológica permite situar al estudiante ante una posibilidad válida de titulación, es que cada una de las fases coinciden con el ciclo de la investigación-acción (I-A), además de retomar algunos otros elementos o instrumentos del llamado paradigma cualitativo de la ciencia. Existen varias posturas en torno a la I-A, sin embargo son comunes en todas ellas la transición de la teoría a la práctica, siendo el conjunto de acciones, planeadas y aplicadas la médula de todas ellas. El investigador por 
tanto tiene un papel fundamental, construye el problema pero también la solución que ejecuta y evalúa. Kemmis la define (citado en Rodríguez, 1999, pág. 52):

"La investigación-acción es una forma de búsqueda autorreflexiva, llevada a cabo por participantes en situaciones sociales (incluyendo educativas), para perfeccionar la lógica y la equidad de a)las propias prácticas sociales o educativas en que se efectúan esas prácticas, b)comprensión de estas prácticas, y c)las situaciones en las que se efectúan esas prácticas.”

En tanto proceso autorreflexivo, es el propio sujeto quien además de encontrar sus áreas de oportunidad debe también encontrar lo que desde su propia individualidad puede hacer para resolverlo. Elliot menciona ocho características de la investigación-acción en la escuela a las que Gregorio Rodríguez, Javier Gil y Eduardo García (1999) denominan InvestigaciónAcción del profesor. De tal forma que retomando estas propuestas la investigación-acción realizada en las escuelas analiza las acciones humanas y las situaciones sociales experimentadas por los docentes, por tal modo que si éstas son inaceptables se entienden como problemáticas, si son susceptibles de cambio se ven como contingentes y de requerir una respuesta práctica son prescriptivas. No obstante el punto de partida es la elaboración de un diagnóstico que debe ser una profunda comprensión de su problema, para entonces adoptar una postura teórica que permita describir el problema y asumir una postura que implique solución.

Siguiendo bajo el mismo discurso habría que acentuar que la interpretación de lo ocurrido en el aula ocurre desde la mirada quienes en ella participan, profesor y alumnos, esto significa que los problemas son contemplados desde los propios actores. Esta metodología no se queda en la sola comprensión de la realidad socioeducativa; se conoce con la tácita finalidad de modificarla, de Restrepo se recupera la idea (Citado en Colmenares, 2008):

"Investigación Acción Educativa es un instrumento que permite al maestro comportarse como aprendiz de largo alcance, como aprendiz de por vida, ya que le enseña cómo aprender a aprender, cómo comprender la estructura de su propia práctica y cómo transformar permanente y sistemáticamente su práctica pedagógica" 
La transformación permanente y sistemática de su práctica pedagógica es su finalidad, sin embargo antes de lograrla hay que ir dando pauta a esa restructuración y no será posible, si no es por medio de identificar las áreas de oportunidad presentes en la labor magisterial, ser aprendiz es a la vez ser sujeto con cierta experiencia abierto al cambio, no puede pensarse en una modificación perenne de la conducta, es un evolución intencional, acreditada con elementos teóricos que permitan como andamiaje sostener la carga estructural de la práctica docente. Desde esta misma perspectiva se identifican al menos 5 etapas de la I-A:

1. Inducción-diagnóstico, en ello se identifica, construye y describe una problemática.

2. Planificación, con la problemática descrita se piensa en un conjunto de situaciones que puedan significar una solución, se genera un plan procesual de acciones.

3. Ejecución del plan, el plan se lleva a la práctica y se recogen evidencias.

4. Reflexión, con los resultados mostrados a través del conjunto de evidencias se analizan aciertos y desatinos.

5. Transformación - re planificación, con base en la reflexión se replantean acciones para iniciar de nueva cuenta el ciclo.

En un intento por amalgamar ideas, el portafolio de experiencias docentes es un proceso de Investigación-acción Pedagógica, no sólo porque es generada por el profesor, tiene a la vez una intención educativa explícita, que debe reflejarse en las acciones llevadas a cabo en el aula y que serán objeto de teorización y reflexión. Es un intento por converger entre teóricos y prácticos de la educación. Dándole al maestrante la posibilidad de que en dicha relación pedagógica, que se genera en la investigación - acción pedagógica, se convierta en protagonista, se sugiere un cambio en la propia práctica; sin embargo, desde la visión de Colmenares (2008) debe para lograrlo cubrir varias fases:

1. Deconstrucción, es una retrospección donde se realiza una crítica detallada, que permitirá generar un diagnóstico.

2. Reconstrucción, realizar un aprendizaje de largo alcance, a través de una propuesta de intervención, lo que implica generar cambios es decir, innovar.

3. Evaluación de la práctica reconstruida, una vez que los cambios han sido generados, se identifican aciertos. 
A través del siguiente esquema se resume la propuesta curricular, explicitando la relación entre las etapas del proceso de innovación, asignaturas, las evidencias del portafolio, las etapas de la investigación-acción y las fases de la I-A pedagógica que dan cuenta del quehacer de los maestrantes como investigadores de su propia práctica.

\begin{tabular}{|c|c|c|c|c|}
\hline $\begin{array}{l}\text { Etapas del } \\
\text { proceso de } \\
\text { innovación }\end{array}$ & $\begin{array}{c}\text { Asignaturas eje } \\
\text { innovación de la } \\
\text { práctica }\end{array}$ & Evidencias del portafolio & $\begin{array}{c}\text { Etapas de la } \\
\text { investigación } \\
\text { acción }\end{array}$ & $\begin{array}{c}\text { Fases de la I-A } \\
\text { Pedagógica }\end{array}$ \\
\hline Caracterización & $\begin{array}{l}\text { Recuperación y } \\
\text { análisis de la } \\
\text { práctica docente. }\end{array}$ & $\begin{array}{l}\text { - } 2 \text { registros de observación. } \\
\text { - Esquema del uso del habla. } \\
\text { - Gráficas del tiempo y el habla. } \\
\text { - Decisiones y pregunta inicial. } \\
\text { - Micro ensayo de primer } \\
\text { orden. } \\
\text { - Micro ensayo de segundo } \\
\text { orden. }\end{array}$ & $\begin{array}{l}\text { Inducción } \\
\text { diagnóstico. }\end{array}$ & Deconstrucción \\
\hline Problematización & $\begin{array}{l}\text { Innovación } \\
\text { educativa I }\end{array}$ & $\begin{array}{l}\text { - Análisis de los elementos } \\
\text { constitutivos y esquema de } \\
\text { arqueología de la clase. } \\
\text { - Preguntas de indagación. } \\
\text { - Revisión de investigaciones } \\
\text { similares (estado del } \\
\text { conocimiento) } \\
\text { - Marco teórico. } \\
\text { - Ruta crítica y ubicar alumnos } \\
\text { Elaborar plan de innovación } \\
\text { (que incluye planeación de } \\
\text { clase) } \\
\text { - Antelar impacto y efecto. }\end{array}$ & Planificación & Reconstrucción \\
\hline Innovación & $\begin{array}{l}\text { Innovación } \\
\text { educativa II } \\
\text { Seminario } \\
\text { titulación }\end{array}$ & $\begin{array}{l}\text { - Aplicación de la propuesta de } \\
\text { intervención. } \\
\text { - Registros de observación de la } \\
\text { intervención. } \\
\text { - Micro ensayo de 1er. Orden y } \\
\text { anexos. } \\
\text { - Micro ensayo de Segundo } \\
\text { Orden y anexos. } \\
\text { - Conclusión final. } \\
\text { - Introducción a cada fase. } \\
\text { - Introducción general al } \\
\text { documento. } \\
\text { - Portafolios a revisión por } \\
\text { lectores. }\end{array}$ & $\begin{array}{l}\text { Ejecución del } \\
\text { plan. } \\
\text { Reflexión } \\
\text { Transformación } \\
\text { - } \\
\text { replanificación. }\end{array}$ & $\begin{array}{l}\text { Evaluación de } \\
\text { la práctica } \\
\text { reconstruida. }\end{array}$ \\
\hline
\end{tabular}

Entre la deconstrucción y la reconstrucción se sustenta la innovación de la práctica, al realizarse un diagnóstico donde se constituye un problema, para proponer solución desde la perspectiva teórica, es necesaria la revisión bibliográfica, empero, de la mano de la 
experiencia del profesor. El conjunto de evidencias de este procedimiento es elemento que da cuenta de la transformación del ejercicio docente, ésta no es posible si no se tienen intenciones diferentes, esa es la perspectiva que permite hablar de innovación en la práctica pedagógica.

Para lograrlo se necesita la individualización de la enseñanza, esto significa que el maestro personalice su propio quehacer, basado en las necesidades de los estudiantes, las del contexto y las que emanan de su propia persona. Incluso aquellas limitantes en las que no se puede intervenir deben aceptarse como parte del contexto y asumir como propias las tareas que sí impliquen un cambio que surja desde el propio sujeto-profesor, recordemos que el objeto de estudio es el quehacer docente así lo explica Anahí Contreras en entrevista realizada el 13 de abril de 2016:

“(El portafolios) Lo realizamos a través de la investigación-acción, aquí recopilamos ciertos aspectos teóricos-metodológicos pero que aparte los tenemos que llevar a la aplicación, hacer observación etnográfica, recuperar, traer, analizar, modificar y volver a aplicar; estamos en un constante ir y venir en nuestro caso estamos forzados a aplicarlo y a analizarlo"

El ciclo de la investigación acción se va realizando y los participantes lo asumen, no sólo como reto, sino como un motivo personal de mejora que implica cambios respecto a lo cotidiano y desde una visión teórica que permita sustentar las acciones, realizarlas de manera intencionadas, formando así hechos educativos.

\section{Resultados obtenidos a través del portafolio de experiencias docentes.}

La mejora de la práctica implica realizar acciones nuevas e intencionadas dentro del aula, mismas que se gestan atendiendo al contexto del grupo en el que serán realizadas, esto es la innovación educativa, recordemos la postura de Pedro Cañal (2002, pág. 11) cuando la define como "conjunto de ideas, procesos y estrategias, más o menos sistematizados, mediante los cuales se trata de introducir y provocar cambios en las prácticas educativas vigentes", concepciones similares emplean Lázaro Uc Mas o Martha Vergara Fregoso, para innovar es necesario generar y aplicar una acción pensada, gestionada y realizada de manera autónoma por el profesor, atendiendo a los problemas de su práctica particular. 
El resultado de este cúmulo de ejercicios es lo que para William Car sería una práctica docente desde un enfoque crítico, Guadalupe Galván (2016, pág. 107) señala lo anterior y comenta al respecto "mientras más sepan los docentes de sus comprensiones y creencias serán más capaces de intencionarlas racionalmente... (la perspectiva crítica) exige una autorreflexión crítica aprendida por los mismos profesores", no podemos hablar de innovación de la práctica educativa, si no se ha realizado primero un diagnóstico, esa es la importancia del proceso descrito en el apartado anterior, pues al ser realizado por el mismo profesor se llega a una intervención sustentada por quien vive la problemática. En voz de quienes han elaborado el portafolios se presentan los siguientes alcances:

"La innovación está muy de la mano con la transformación, entonces podemos hablar de una renovación porque si hablamos de renovación es cambiar la teoría de las practicas, entonces me di cuenta que los chicos están en esa etapa de clasificación y conservación que era donde los ubique y lo que observé es que los alumnos que estaban entre la uno pues dieron ese salto a la etapa dos pues si vi que hubo un avance.” (López, 2016)

“A lo mejor no dar un pasote así por ejemplo de una etapa A a una etapa C pero si se pueden ir dando pequeños avances la ruta crítica; yo desarrolle mi propia ruta crítica, vi que los chicos en la última semana pasaron a la siguiente etapa a donde yo los quería llevar” (Contreras, 2016)

Dos aspectos a retomar, la intención de la innovación es que los alumnos alcancen ciertos aprendizajes, para poder establecer no solo los alcances de la intervención, sino, también para describir las habilidades con que cuentan los estudiantes se elabora una ruta crítica, en términos semejantes la compararíamos con una taxonomía, es decir, una serie de etapas que incluyen el conjunto de habilidades, físicas, cognitivas, de lenguaje, etc. (eso corresponde a intencionalidades del investigador)que permiten situar a los estudiantes en un nivel y redirigir hacia donde se quieren llevar. En función de ello es que se puede establecer si la propuesta de innovación-intervención alcanza los objetivos propuestos para los estudiantes. En voz de los entrevistados, se percibe la transición de una etapa a otra. Para mostrar la transición en el proceso de formación y elaboración del portafolio se presentan los cuestionamientos que dan forma al documento: 


\begin{tabular}{|c|c|c|c|}
\hline \multirow[t]{2}{*}{ Nombre } & \multicolumn{3}{|c|}{ Preguntas } \\
\hline & Inicial & Indagación & Innovación \\
\hline $\begin{array}{l}\text { Rosa } \\
\text { Sánchez } \\
\text { Titulada }\end{array}$ & $\begin{array}{l}\text { ¿Cómo son las } \\
\text { estrategias que } \\
\text { utiliza } \\
\text { el profesor para } \\
\text { propiciar la } \\
\text { comprensión de los } \\
\text { cálculos realizados? }\end{array}$ & $\begin{array}{l}\text { ¿Cómo son las acciones académicas } \\
\text { que utiliza el profesor de } \\
\text { matemáticas } \\
\text { financieras para propiciar la } \\
\text { comprensión de los diversos cálculos } \\
\text { financieros } \\
\text { realizados por los estudiantes del } \\
\text { grupo 5ECO01? }\end{array}$ & $\begin{array}{l}\text { ¿A través de qué acciones } \\
\text { académicas utilizadas por el } \\
\text { profesor de matemáticas } \\
\text { financieras el alumno puede } \\
\text { recorrer el camino de una etapa } \\
\text { de aplicación mecánica de los } \\
\text { diversos cálculos financieros a } \\
\text { un aprendizaje significativo? }\end{array}$ \\
\hline $\begin{array}{l}\text { Leonardo } \\
\text { Castro } \\
\text { Titulado }\end{array}$ & $\begin{array}{l}\text { ¿En qué medida el } \\
\text { uso e } \\
\text { implementación de } \\
\text { las TIC fomenta el } \\
\text { aprendizaje } \\
\text { colaborativo? }\end{array}$ & $\begin{array}{l}\text { ¿En qué procesos o actividades de } \\
\text { aprendizaje se ve reflejada la utilidad } \\
\text { de la clase con el aprendizaje } \\
\text { colaborativo? ¿Qué oportunidades y } \\
\text { ventajas ofrece el uso de las } \\
\text { tecnologías de información y } \\
\text { comunicación para la estimulación } \\
\text { del aprendizaje colaborativo? }\end{array}$ & $\begin{array}{l}\text { ¿A través del uso las TIC en qué } \\
\text { procesos o actividades } \\
\text { académicas se ve reflejado } \\
\text { la implementación del } \\
\text { aprendizaje } \\
\text { pragmático/colaborativo? }\end{array}$ \\
\hline $\begin{array}{l}\text { Anahí } \\
\text { Contreras }\end{array}$ & $\begin{array}{l}\text { ¿De qué manera el } \\
\text { profesor de inglés } \\
\text { integra en } \\
\text { consideración las } \\
\text { inteligencias } \\
\text { múltiples y los } \\
\text { diferentes estilos } \\
\text { de aprendizaje de } \\
\text { los estudiantes } \\
\text { para facilitar y } \\
\text { desarrollar las } \\
\text { cuatro habilidades } \\
\text { del idioma inglés? }\end{array}$ & $\begin{array}{l}\text { ¿Qué elementos paralingüísticos y } \\
\text { metalingüísticos son considerados } \\
\text { por el profesor de inglés en el diseño } \\
\text { de UDA para el bloque } 3 \text { del nivel } 0 \text {, } \\
\text { para el logro de los objetivos } \\
\text { generales y específicos? }\end{array}$ & $\begin{array}{l}\text { ¿Cómo permiten las estrategias } \\
\text { didácticas y la metodología de } \\
\text { enseñanza, a los estudiantes, } \\
\text { pasar de la etapa de Desarrollo } \\
\text { Gramatical, en la sub-etapa } \\
\text { Telegráfica a la siguiente etapa } \\
\text { de Producción del Lenguaje, en } \\
\text { la sub-etapa de Desarrollo de la } \\
\text { Habilidad Pragmática y } \\
\text { Comprensión de la Relatividad } \\
\text { Lingüística? }\end{array}$ \\
\hline Esther Lerdo & $\begin{array}{l}\text { ¿Será que a los } \\
\text { docentes no les } \\
\text { preocupa } \\
\text { incursionar en la } \\
\text { implementación de } \\
\text { valores en su } \\
\text { quehacer docente? }\end{array}$ & $\begin{array}{l}\text { ¿Qué herramienta didáctica apoyada } \\
\text { en la creatividad, puede utilizar el } \\
\text { docente dedicado al área de las } \\
\text { humanidades en el nivel medio } \\
\text { superior para propiciar en los } \\
\text { alumnos un conocimiento de sus } \\
\text { actitudes y la construcción de sus } \\
\text { propios valores? }\end{array}$ & $\begin{array}{l}\text { ¿A través de qué estrategias } \\
\text { didácticas creativas el docente } \\
\text { del nivel medio superior en el } \\
\text { área de las humanidades - } \\
\text { contendidos actitudinal-valoral, } \\
\text { fomenta el tránsito de sus } \\
\text { alumnos del nivel de } \\
\text { conocimientos al nivel de } \\
\text { comprensión? }\end{array}$ \\
\hline
\end{tabular}

Las preguntas iniciales centran al estudiante en una posible temática a investigar, al tiempo le permiten ir identificando dentro de su práctica una situación susceptible a ponerse en crítica, a fin de convertirla en un problema a resolver a través de la propuesta de innovación-intervención, al fin de entender que "el análisis y la crítica de la propia práctica son indispensables en este proceso y que esto no se logra sólo con la reproducción de teorías y aplicación de técnicas, sino indagando las problemáticas cotidianas de cada 
docente" (Lozano, Mercado, 2014, pág. 56). Es una síntesis en las que a la par de los elementos teóricos se pone en juego la experiencia de los profesores para resolver un problema que en esencia les pertenece, en pro de la mejora de los aprendizajes de sus estudiantes.

\section{Conclusión}

La elaboración del portafolio de experiencia docente es llevado a cabo por los estudiantesprofesores en las materias que conforman el eje de innovación en la práctica en las comunidades de aprendizaje, bajo la guía de las coordinadoras del eje, quienes son también las docentes de la asignatura. Como se ha mostrado el recorrido, se hace ciñéndose a la metodología de la investigación-acción del profesor (pedagógica). Desde la recuperación de la práctica a través de registros de clase a fin de construir un problema surgido de las aulas, un momento de autorreflexión, en el que se pone en tela de juicio el ejercicio cotidiano, observando siempre las acciones realizadas por el profesor. Pues es entorno a él que se construirá la problemática y se propondrá la solución desde sus propias posibilidades.

El maestrante hace investigación educativa, una que va más allá de la revisión de teorías, el reto se concibe entorno a la reflexión de su propio contexto donde se genera una amalgama entre la experiencia del profesor, las características del contexto y una visión teórica desde la que se planean, ejecutan y evalúan un conjunto de acciones, que al romper con lo cotidiano se convierte en innovación educativa.

El portafolios de experiencia docente en tanto conjunto de evidencias realizadas en las asignaturas de eje de innovación de la práctica da cuenta por un lado de la formación recibida en el posgrado y por otro lado de la búsqueda por mejorar la docencia. Por eso es que se trata de una modalidad de titulación pues da cuenta de lo realizado en dos años, en tanto proceso formativo da cuenta del conjunto de habilidades que se desarrollaron y cómo es que éstas influyen en el desarrollo profesional, que pueden constatarse en los aprendizajes logrados en los niños, adolescentes o jóvenes, a través de la puesta en marcha del conjunto de actividades intencionadas durante la intervención.

Las etapas mostradas en el documento caracterización, problematización e innovación, confluyen con la deconstrucción, reconstrucción y evaluación, etapas de la investigación- 
acción pedagógica, existe pues una metodología clara en cuanto a la elaboración del portafolios, y sin duda con miras a la mejora del quehacer docente, elemento principal del objetivo de la Maestría en Desarrollo Docente.

\section{Bibliografía}

Barberá, E. (2005). CALIFICAR EL APRENDIZAJE MEDIANTE LA EVALUACIÓN POR PORTAFOLIOS. Perspectiva educacional, 70-84.

Bozu, Z. (2012). Cómo elaborar un portafolio para mejorar la docencia universitaria. Barcelona: Octaedro.

Cañal de León, P., \& et all. (2002). La innovación educativa. Madrid: Akal.

Colmenares, M., \& Piñeiro, L. (2008). La investigación acción, una herramienta metodológica heurística para la comprensión - transformación de realidades socioeducativas. Laurus, 96 - 114.

Díaz, F. (2012). Diseño tecnopedagógico de portafolios electrónicos de aprendizaje: Una experiencia con estudiantes. Revista electrónica de investigación educativa., 103 117.

Galván, G., Ibarra, L., van Dijk Kocherthaler, S., \& Lozano, M. (2016). (Re) descubriendo los significados de las prácticas docentes. México: UG.

Lozano, I., \& Mercado, E. (2014). Cómo investigar la práctica docente. Orientaciones para elabora el documento recepcional. Estado de México: ISCEM.

Mardones, J., \& Ursua, M. (1991). Filosofía de las Ciencias Humanas y Sociales. Barcelona: Anthropos.

Porta, L., \& Silva, M. (octubre de 2003). La investigación cualitativa: el anállisis de contenido en la investigación educativa. Obtenido de anthropostudio.com: http://anthropostudio.com/wp-content/uploads/2015/04/Luis-Porta.-Lainvestigaci\%C3\%B3n-cualitativa.-El-An\%C3\%A1lisis-de-Contenido-en-lainvestigaci\%C3\%B3n-educativa..pdf

Quecedo, R., \& Castaño, C. (2002). Introducción a la metodología de la investigación cualitativa. Revista de psicodidáctica, 5 - 39.

Rodíguez, G. (1999). Métodos de Investigación Cualitativa. España: Aljibe.

Stenhause, L. (1985). Investigación y desarrollo del currículum. Madrid: Morata. 
Taylor, S., \& Bogdan, R. (1989). Introducción a los métodos cualitativos de la investigación. Barcelona: Paidos.

UG. (2014 de febrero de 27). Maestría en Desarrollo Docente. Obtenido de División de Ciencias Sociales y Humanidades: www.maestriadesarrollodocente.ugto.mx 